\title{
Treating resistant hypertension: role of renal denervation
}

This article was published in the following Dove Press journal:

Integrated Blood Pressure Control

10 September 2013

Number of times this article has been viewed

\section{Daniel Urban \\ Sebastian Ewen \\ Christian Ukena \\ Dominik Linz \\ Michael Böhm \\ Felix Mahfoud}

Department of Internal Medicine III, Cardiology, Angiology and Intensive Care Medicine, University Hospital of Saarland, Homburg, Saarland, Germany
Correspondence: Felix Mahfoud Department of Internal Medicine III, Cardiology, Angiology and Intensive Care Medicine, University Hospital of Saarland, Kirrberger Str, Geb 40, 6642I Homburg, Saarland, Germany

$\mathrm{Tel}+49684 \mid \quad 1621346$

Fax +49 684I I6 I32II

Email felix.mahfoud@uniklinikumsaarland.de
Abstract: Arterial hypertension is the most prevalent risk factor associated with increased cardiovascular morbidity and mortality. Although pharmacological treatment is generally well tolerated, $5 \%-20 \%$ of patients with hypertension are resistant to medical therapy, which is defined as blood pressure above goal $(>140 / 90 \mathrm{mmHg}$ in general; $>130-139 / 80-85 \mathrm{mmHg}$ in patients with diabetes mellitus; $>130 / 80 \mathrm{mmHg}$ in patients with chronic kidney disease) despite treatment with $\geq 3$ antihypertensive drugs of different classes, including a diuretic, at optimal doses. These patients are at significantly higher risk for cardiovascular events, in particular stroke, myocardial infarction, and heart failure, as compared with patients with nonresistant hypertension. The etiology of resistant hypertension is multifactorial and a number of risk factors have been identified. In addition, resistant hypertension might be due to secondary causes such as primary aldosteronism, chronic kidney disease, renal artery stenosis, or obstructive sleep apnea. To identify patients with resistant hypertension, the following must be excluded: pseudo-resistance, which might be due to nonadherence to medical treatment; white-coat effect; and inaccurate measurement technique. Activation of the sympathetic nervous system contributes to the development and maintenance of hypertension by increasing renal renin release, decreasing renal blood flow, and enhancing tubular sodium retention. Catheter-based renal denervation $(\mathrm{RDN})$ is a novel technique specifically targeting renal sympathetic nerves. Clinical trials have demonstrated that RDN significantly reduces blood pressure in patients with resistant hypertension. Experimental studies and small clinical studies indicate that RDN might also have beneficial effects in other diseases and comorbidities, characterized by increased sympathetic activity, such as left ventricular hypertrophy, heart failure, metabolic syndrome and hyperinsulinemia, atrial fibrillation, obstructive sleep apnea, and chronic kidney disease. Further controlled studies are required to investigate the role of RDN beyond blood pressure control.

Keywords: resistant hypertension, secondary hypertension, sympathetic nervous system, renal denervation, symplicity

\section{Introduction}

High blood pressure is a major risk factor increasing the incidence of stroke, myocardial infarction, and heart failure, thus leading to higher mortality. Approximately $25 \%$ of adults worldwide are affected by elevated blood pressure and it is estimated that hypertension causes $13 \%$ of all deaths worldwide. ${ }^{1}$ About $5 \%-20 \%$ of all patients with hypertension are resistant to medical treatment. ${ }^{2}$ These patients are at significantly higher risk for cardiovascular events than patients with nonresistant hypertension. ${ }^{3}$ Activation of the sympathetic nervous system crucially contributes to the development of hypertension by enhancing renin release from the juxtaglomerular apparatus, reducing renal blood flow, and increasing tubular sodium retention. ${ }^{4-6}$ Renal denervation 
(RDN) is a new interventional approach, developed to selectively interrupt renal sympathetic nerves. Recent studies have indicated that this procedure significantly reduces blood pressure in patients with resistant hypertension without major complications in 98\% (201/209) of cases included in the Symplicity HTN-1 and Symplicity HTN-2 trials. ${ }^{7,8}$ This review will discuss how to identify patients with resistant hypertension and will highlight RDN as novel treatment option for these patients.

\section{Definition}

Resistant hypertension is defined as blood pressure above goal (>140/90 mmHg; >130-139/80-85 mmHg in patients with diabetes mellitus; $>130 / 80 \mathrm{mmHg}$ in chronic kidney disease), despite treatment with $\geq 3$ antihypertensive drugs of different classes, including a diuretic, at optimal doses. ${ }^{2,9}$ The American Heart Association also includes in the definition patients whose blood pressure is controlled with the use of $\geq 4$ antihypertensive agents. Although this definition is to some extent arbitrary, it helps to identify patients at high cardiovascular risk requiring close follow-up by a specialist. Of note, resistant hypertension is not the same as uncontrolled hypertension, as the latter also includes patients who are not at goal due to poor adherence, inadequate treatment regimen (eg, $\leq 3$ antihypertensive agents) or have secondary hypertension. ${ }^{2}$

\section{Epidemiology}

The exact prevalence of resistant hypertension is unknown and its assessment would require large prospective studies using forced titration. ${ }^{1,2}$ However, data from cross-sectional studies and hypertension outcomes studies allow a rough estimation of the prevalence of resistant hypertension. In the 2003-2008 National Health and Nutrition Examination Survey, the prevalence of resistant hypertension was $8.9 \%$ in all hypertensive subjects and $12.8 \%$ in treated hypertensive subjects. ${ }^{10}$ Of these subjects, only $30 \%$ were controlled ( $<140 / 90 \mathrm{mmHg}$ with intake of $\geq 4$ antihypertensive agents). Data from the Framingham Heart Study showed that only $48 \%$ of antihypertensive drug-treated participants were controlled. ${ }^{11}$ Data compiled from four German crosssectional studies indicated a prevalence of resistant hypertension of $18 \%$ in men and $22 \%$ in women. ${ }^{12}$

The Anglo-Scandinavian Cardiac Outcomes Trial, which included over 19,000 subjects, compared the effect of a combination of a beta-blocker (atenolol) and a thiazide diuretic (bendroflumethiazide) versus a calcium channel blocker (amlodipine) and an angiotensin-converting enzyme inhibitor (perindopril) on cardiovascular events. ${ }^{13}$ During a median follow-up of approximately 5 years, 35\% of previously untreated and $50 \%$ of previously treated subjects developed resistant hypertension. ${ }^{14}$ This surprisingly high prevalence might be explained by the fact that subjects in the AngloScandinavian Cardiac Outcomes Trial were relatively old (mean age 65 years) and at high cardiovascular risk (prior cardiovascular events and/or multiple risk factors), thus representing a cohort that is per se difficult to treat. In addition, half did not receive a thiazide diuretic, possibly facilitating the development of resistant hypertension. Nevertheless, these data indicate that, with proper dose titration, a considerable number of patients might in fact be resistant to antihypertensive treatment. ${ }^{15}$

Finally, according to a recently published retrospective cohort study including more than 200,000 subjects with incident hypertension in whom antihypertensive treatment was initiated between 2002 and 2006, the incidence of resistant hypertension was $1.9 \%$ in a median of 1.5 years from initial treatment. ${ }^{3}$

Table I Causes of resistant hypertension

Risk factors
Older age
High systolic blood pressure
Obesity
High salt consumption
Chronic renal disease
Diabetes mellitus
Left ventricular hypertrophy
Female sex
Interfering medications and substances
Nonsteroidal anti-inflammatory drugs
Corticosteroids
Sympathomimetics
Amphetamines
Oral contraceptives
Cyclosporines
Tacrolimus
Erythropoietin
Tricyclic antidepressants
Alcohol
Licorice
Secondary causes
Common
Obstructive sleep apnea
Chronic renal disease
Primary aldosteronism
Renal artery stenosis
Uncommon
Pheochromocytoma
Cushing's syndrome
Hyperparathyroidism
Aortic coarctation

Older age

High systolic blood pressure

Obesity

Chronic renal disease

Diabetes mellitus

Left ventricular hypertrophy

Nonsteroidal anti-inflammatory drugs

Corticosteroids

Sympathomimetics

Amphetamines

Cyclosporines

Tacrolimus

Erythropoieti

Alcohol

Licorice

Secondary causes

Common

Obstructive sleep apnea

Chronic renal disease

Primary aldosteronism

Renal artery stenosis

Aortic coarctation 


\section{Etiology}

The etiology of resistant hypertension is multifactorial. A number of risk factors, summarized in Table 1, have been identified, including age, female sex, obesity, high systolic blood pressure, diabetes mellitus, chronic renal disease, and left ventricular hypertrophy. ${ }^{2}$ Another factor, which impedes adequate blood pressure control, is suboptimal combination or underuse of antihypertensive drugs. ${ }^{16}$ Moreover, drug interactions might contribute to resistant hypertension by causing sodium retention, extracellular water expansion, or direct activation of the sympathetic nervous system (Table 1). In particular, nonsteroidal anti-inflammatory drugs have been shown to facilitate the development of resistant hypertension by increasing sodium and water retention and attenuating the effect of numerous antihypertensive drugs. ${ }^{17,18}$ In addition to nonsteroidal anti-inflammatory drugs, other drugs such as glucocorticoids, sympathomimetics, estrogens, contraceptives, antidepressants, and erythropoietin can significantly increase blood pressure by various mechanisms. ${ }^{19}$

\section{Secondary causes for resistant hypertension}

Resistant hypertension might also result from secondary causes (Table 1). In $14 \%-21 \%$ of patients with resistant hypertension, primary hyperaldosteronism was found and the addition of mineralocorticoid antagonists were shown to significantly reduce blood pressure in this cohort. ${ }^{15,20}$

Obstructive sleep apnea (OSA) syndrome has been observed in more than two-thirds of patients with resistant hypertension, while only $38 \%$ of patients with controlled hypertension have been found to meet the criteria of this syndrome..$^{21,22}$

Chronic kidney disease is not only a consequence of resistant hypertension but also an important cause. Less than 15\% of patients with chronic kidney disease are controlled to target blood pressure values ( $<130 / 90 \mathrm{mmHg}$ ), despite taking $\geq 3$ antihypertensive agents. ${ }^{2}$ In approximately $10 \%$ of patients with resistant hypertension aged over 65 years, a significant renal artery stenosis (ie, $>70 \%$ ) was documented. ${ }^{2}$

Rare causes of hypertension are pheochromocytoma, Cushing's syndrome, vasculitis, thyrotoxic crisis, and coarctation of the aorta. ${ }^{23}$ Therefore, secondary causes of resistant hypertension have to be identified, as these patients might benefit from a specific therapy, rather than from RDN.

\section{Pseudo-resistance}

Blood pressure can be overestimated as a consequence of inaccurate measurement technique. The most common causes of overestimated blood pressure are using a cuff that is too small for the patient's arm and measuring blood pressure before the patient is sitting quietly. ${ }^{24}$ Another cause of pseudo-resistance is the so-called white-coat effect. This means that patients have normal blood pressure at home or during ambulatory monitoring but have an office blood pressure $>140 / 90 \mathrm{mmHg}$. This phenomenon is observed in $20 \%-30 \%$ of patients with resistant hypertension. ${ }^{25,26}$

However, the most commonly seen cause of pseudoresistance is nonadherence to prescribed antihypertensive therapy ${ }^{27}$ Around $40 \%$ of patients with first incidence of hypertension will stop their antihypertensive therapy within the first year. During 5-10 years of follow-up, less than $40 \%$ of patients will continue the recommended treatment. ${ }^{2}$ This might be for various reasons, such as side effects, ignorance of the consequences of uncontrolled hypertension, or a poor doctor-patient relationship. In contrast, guidance from a specialist appears to increase adherence rates. A retrospective study conducted at a hypertension clinic revealed that nonadherence was the leading cause of uncontrolled hypertension in only $16 \%$ of patients. ${ }^{28}$

\section{Diagnosis}

The diagnosis of resistant hypertension requires exclusion of both pseudo-resistance and reversible or organic causes (Figure 1). Therefore, evaluation of medical history with a focus on duration, severity, and progression of hypertension as well as on treatment adherence and response to prior antihypertensive agents is essential. Every patient with suspected resistant hypertension

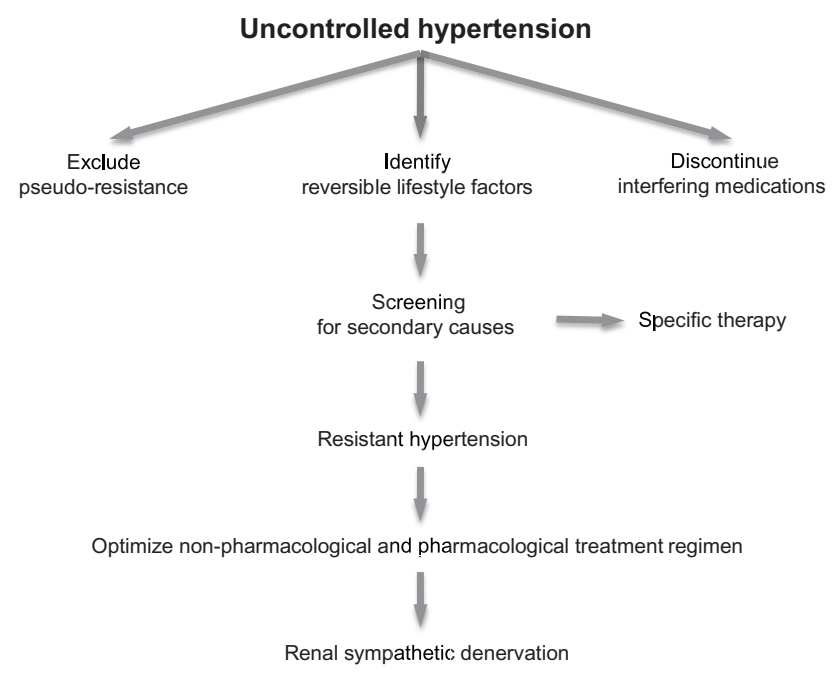

Figure I Proposed screening algorithm for patients with uncontrolled hypertension. Notes: Modified from Mahfoud F, Himmel F, Ukena C, Schunkert H, Böhm M, Weil J. Treatment strategies for resistant arterial hypertension. Dtsch Arztebl Int. 20I I; 108(43):725-731. ${ }^{23}$ 
should undergo ambulatory blood pressure measurement, blood testing (serum electrolytes, glucose, and creatinine or cystatin $\mathrm{C}$ ), and urinary testing (urinary albumin excretion and salt excretion). Moreover, evaluation of resistant hypertension should include screening for primary hyperaldosteronism, comprising determination of the aldosterone-renin ratio. For interpretation, potential drug interactions have to be taken into account. In case of an aldosterone-renin ratio above 50, diagnostic imaging (computed tomography or magnetic resonance imaging) and adrenal vein sampling might be necessary to exclude primary hyperaldosteronism. Noninvasive imaging of the renal arteries has to be considered in young patients with the notion of fibromuscular dysplasia and in older patients with suspicion of atherosclerotic renal artery disease. ${ }^{23}$

\section{Prognosis}

First evidence for the poor prognosis of patients with uncontrolled hypertension came from the early Veterans Administration cooperative studies, showing that use of a triple antihypertensive therapy reduced cardiovascular events during 18 months of follow-up by $96 \%$ compared with placebo in patients with severe hypertension. ${ }^{29}$ However, the definite impact of resistant hypertension on prognosis was unknown for decades. In a recent retrospective cohort study, Daugherty et $\mathrm{al}^{3}$ demonstrated that patients with resistant hypertension are at significantly higher risk for cardiovascular events than patients with nonresistant hypertension (hazard ratio, 1.47; 95\% confidence interval, 1.33-1.62), pointing to the requirement for effective treatment strategies in that high-risk patient population.

\section{Renal sympathetic denervation Pathophysiological background}

It is well established that hyperactivity of the sympathetic nervous system initiates and sustains the blood pressure elevation in patients with different forms of hypertension, including systole-diastolic and isolated systolic hypertension; white-coat and masked hypertension; dipping, non-dipping and reverse dipping conditions; and resistant hypertension. ${ }^{6}$ Activity of the sympathetic nervous system correlates with the severity of some forms of hypertension, such as essential and secondary hypertension. ${ }^{30}$ Kidneys are targeted by both afferent and efferent sympathetic innervation (Figure 2). ${ }^{5}$ Increased sympathetic nervous stimulation enhances renal renin release of the juxtaglomerular apparatus by activation of $\beta 1$-adrenoceptors, reduces renal blood flow mediated by $\alpha 1 \mathrm{~A}$-adrenoceptors, and increases tubular sodium retention

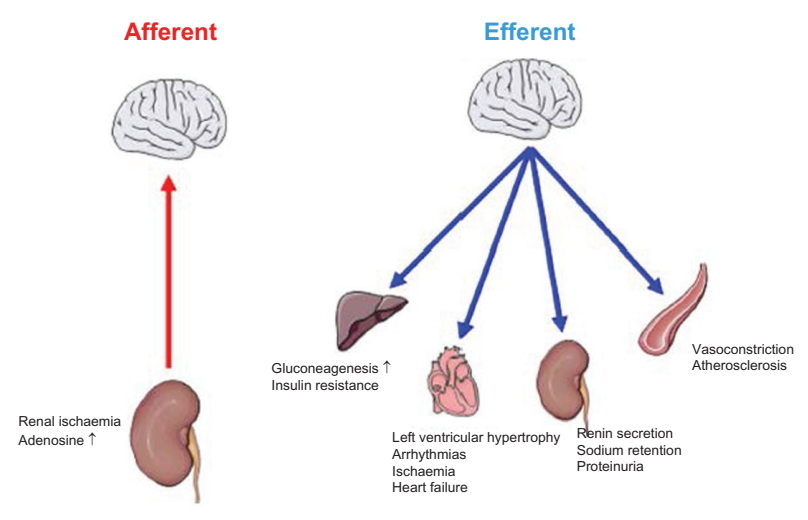

Figure 2 Afferent and efferent sympathetic nerve fibers reach the kidneys along with the renal arteries. Increased sympathetic nervous outflow enhances renal renin release, reduces renal blood flow, and increases tubular sodium retention. Afferent nerve fibers connect the kidneys with the central nervous system. Activation of renal afferents elevates sympathetic nervous outflow to the kidney and other downstream organs. Note: Reproduced from Percutaneous renal denervation: new treatment option for resistant hypertension and more?, Ewen S, Ukena C, Böhm M, Mahfoud F, 99, I | 29-I I34, copyright 2013 with permission from BM] Publishing Group Ltd.

via stimulation of $\alpha 1 \mathrm{~B}$-adrenoceptors. ${ }^{5,31-33}$ Afferent renal nerve fibers connect the kidney with the central nervous system. Activation of renal afferents increases central sympathetic nervous activity targeting the vasculature, the heart, and other peripheral organs. ${ }^{34}$

\section{Procedure}

Recently, a catheter-based approach has been developed selectively targeting the renal sympathetic nerves. Five CE-marked devices for renal sympathetic denervation were hitherto available (Symplicity [Medtronic, Mountain View, CA, USA], EnligHTN [St Jude Medical, Little Canada, MN, USA], V2 [Vessix, Laguna Hills, CA, USA], OneShot [Covidien, Dublin, Ireland] and Paradise [ReCor Medical Technology, Menlo Park, CA, USA]).

The most clinical experience and evidence exist for Medtronic's Symplicity device. The radiofrequency catheter is inserted percutaneously via the femoral artery and advanced into the renal arteries under fluoroscopy using a guiding catheter (Figure 3). After placement, the catheter is withdrawn from distal to proximal segments and four to eight ablations are administered within each artery. Focally applied heat (maximum $70^{\circ} \mathrm{C}$ ) destroys the sympathetic nerve fibers located in the adventitia. Simultaneously, the high renal blood flow cools the vessel wall. Due to the close proximity of sympathetic nerve fibers with $\mathrm{C}$ pain fibers, the procedure is painful and requires analgosedation-anesthesia. The development of novel devices, such as multipolar electrodes or ultrasound systems might reduce both the procedural time and pain, thus reducing the demand for analgosedation-anesthesia. 


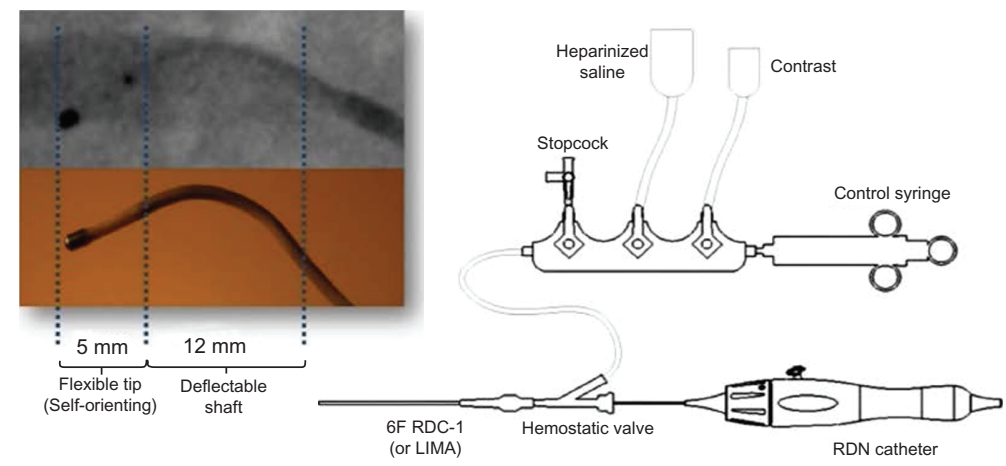

Figure 3 Manifold set-up and Symplicity renal denervation (RDN) catheter tip (Medtronic, Mountain View, CA, USA). Abbreviations: LIMA, left internal mammary artery; RDC, renal double curve. Note: Reproduced with permission from Medtronic. Medtronic.

From an interventional perspective, RDN is a simple technique to implement. However, RDN should be performed only by trained vascular interventionalist in a well-equipped catheterization laboratory. ${ }^{35}$ Operators should be able to handle periprocedural complications such as renal artery dissection or perforation. Appropriate expertise could be assumed in centers that perform $>25$ renal interventions per year. ${ }^{35}$ Specific training courses, providing important information about the technique, are widely available.

\section{Patient selection}

Following the Simplicity HTN-1 and Simplicity HTN-2 trials, RDN was introduced widely in Europe and Australia. Recently, a number of consensus papers have been published thoroughly describing the selection of patients for RDN. ${ }^{35-37}$

Before RDN is considered for a patient with resistant hypertension, the patient should have been seen by a hypertension expert in a specialized center (such as a Hypertension Excellence Centre [see http://www.eshonline.org/ Communities/CentresList.aspx] $).{ }^{35}$ Briefly, RDN should be considered in patients with severe resistant hypertension, defined as office systolic blood pressure (SBP) $\geq 160 \mathrm{mmHg}$ ( $\geq 150 \mathrm{mmHg}$ in patients with type 2 diabetes) despite treatment with $\geq 3$ antihypertensive drugs of different classes, including a diuretic, at optimal doses. Elevated office SBP should be confirmed by ambulatory blood pressure monitoring. Reversible lifestyle factors have to be identified and interfering medications should be discontinued (Figure 1). In addition, pseudo-resistance and secondary causes for elevated blood pressure must be systematically excluded (Table 1). Noninvasive imaging of renal artery (duplex ultrasound or magnetic resonance imaging) should be performed to check whether the procedure is anatomically feasible (see the "Contraindications" section).

\section{Clinical studies}

In the multicenter safety and proof-of-principle study Symplicity HTN-1, 45 patients with resistant hypertension (mean blood pressure 177/101 mmHg despite taking an average of 4.7 antihypertensive agents) underwent RDN.? The primary endpoints of the study were the periprocedural and long-term safety of the treatment and blood pressurelowering effect of the intervention. After 4 weeks, a significant reduction in office SBP and diastolic blood pressure of 14 and $10 \mathrm{mmHg}$, respectively, was observed. At 12-month follow-up, the reductions were 27 and $17 \mathrm{mmHg}$, respectively. Data from the long-term follow-up demonstrated a sustained decrease of office SBP and diastolic blood pressure by 31 and $16 \mathrm{mmHg}$, respectively (Table $2 ; \mathrm{n}=34 ; P<0.01$ ) after 36 months, arguing against a substantial re-innervation of renal arteries ${ }^{38}$ Renal norepinephrine spillover measured 15-30 days after RDN was reduced by $47 \%(n=10)$, strongly suggesting an inhibition of renal sympathetic nervous activity. ${ }^{7}$

The following multicenter randomized Symplicity HTN-2 trial included 106 patients with resistant hypertension. ${ }^{8}$ Patients were randomized 1:1 to a treatment group (RDN and continuation of drug treatment) or a control group (continuation of drug treatment). Patients' mean blood pressure at baseline was 178/96 $\mathrm{mmHg}$, despite taking 5.3 antihypertensive drugs. At 6-month follow-up, blood pressure was reduced by $32 / 12 \mathrm{mmHg}(P<0.0001)$ in the treatment group, while no change was observed in the control group. Analysis of 24-hour ambulatory blood pressure measurement showed a significant reduction of mean blood pressure by $11 / 7 \mathrm{mmHg}$ in the treatment group, while there was no change in the control group $(P=0.007 ; \mathrm{n}=20)$. Response to treatment, defined as reduction in SBP $>10 \mathrm{mmHg}$ after 6 months, was found in $84 \%$ of patients.

Recently, the 1-year results from Symplicity HTN-2 were published, confirming a sustained blood pressure 
Table 2 Long term effect of renal denervation on blood pressure

\begin{tabular}{|c|c|c|c|c|}
\hline & $\begin{array}{l}\text { Change in Systolic BP } \\
(\mathrm{mmHg})(95 \% \mathrm{Cl})\end{array}$ & $P$-value & $\begin{array}{l}\text { Change in Diastolic BP } \\
(\mathrm{mmHg})(95 \% \mathrm{CI})\end{array}$ & $P$-value \\
\hline I Month $(n=|4|)$ & $-19(-22.1,-15.9)$ & $<0.01$ & $-10(-12.0,-8.0)$ & $<0.01$ \\
\hline 3 Months $(n=\mid 45)$ & $-22(-25.4,-18.6)$ & $<0.01$ & $-11(-13.2,-8.8)$ & $<0.01$ \\
\hline 6 Months $(n=139)$ & $-21(-25.9,-16.1)$ & $<0.01$ & $-9(-12.1,-5.9)$ & $<0.01$ \\
\hline 9 Months $(n=90)$ & $-23(-27.8,-18.2)$ & $<0.01$ & $-12(-14.8,-9.2)$ & $<0.01$ \\
\hline 12 Months $(n=132)$ & $-27(-30.7,-23.3)$ & $<0.01$ & $-13(-15.4,-10.6)$ & $<0.01$ \\
\hline I 8 Months $(n=58)$ & $-26(-31.2,-20.8)$ & $<0.01$ & $-13(-16.2,-9.8)$ & $<0.01$ \\
\hline 24 Months $(n=44)$ & $-3 \mathrm{I}(-36.3,-25.7)$ & $<0.01$ & $-16(-20.4,-11.6)$ & $<0.01$ \\
\hline
\end{tabular}

reduction after 12 months' follow-up. ${ }^{39}$ Six months after randomization, patients from the control group underwent RDN. Corresponding to initially treated patients, blood pressure was reduced by $24 / 8 \mathrm{mmHg}(P<0.0001)$ in the crossover group. ${ }^{39} \mathrm{~A}$ high SBP has been identified as a predictor of response. ${ }^{40}$ In addition, intake of centrally acting sympatholytics was associated with response to RDN in the Symplicity HTN-2 trial, which was unexpected to some extent, as one might have thought that drugs acting on the same pathophysiological mechanism as RDN are more effective. This phenomenon might be explained by the fact that RDN targets compensatory mechanisms such as sodium and water retention, which are activated in patients taking centrally acting sympatholytics.

\section{Safety}

RDN was done without complications in 98\% (201/206) of patients systematically followed in Symplicity-HTN1 and Symplicity-HTN2., ${ }^{7,41}$ The following complications were reported: four cases of femoral artery pseudoaneurysm, which were all able to be treated conservatively, and one renal artery dissection during positioning of the guiding catheter, which was successfully treated with stenting. In addition, some minor complications, including one urinary tract infection, one case of back pain, one prolongation of hospital stay because of paresthesias, and a vasovagal reaction in seven patients during intervention. RDN did not affect renal function (cystatin $\mathrm{C}$ estimated glomerular filtration rate [eGFR]) in patients with preserved renal function at 3- and 6-month follow-up. ${ }^{42}$

Dörr et $a l^{43}$ investigated the effect of RDN on structural and functional renal damage by using highly sensitive biomarkers (urinary neutrophil gelatinase-associated lipocalin and kidney injury molecule-1). In 62 patients with preserved renal function (average baseline eGFR of $79.3 \pm 27.3 \mathrm{~mL} / \mathrm{min} / 1.73 \mathrm{~m}^{2}$ ), no significant increase in the already mentioned biomarkers, creatinine, or eGFR was found at 24 hours, 48 hours, and 3 months after RDN.

Recently, two case reports of secondary blood pressure rises after renal denervation were reported. ${ }^{44,45}$ In both patients, a significant renal artery stenosis was detected in the treated vessels by angiography. However, both patients suffered from generalized atherosclerosis, so it is likely that the stenosis was due to a naturally occurring progress of an atherosclerotic lesion rather than RDN. Single case studies are of limited value to assess the importance of complications.

Repeated spiroergometry in 46 patients demonstrated that RDN reduces mean blood pressure at rest and during exercise without affecting blood pressure adaption or inducing chronotropic incompetence. ${ }^{46}$

\section{Contraindications}

RDN should not be performed in patients with anatomically unsuitable renal arteries (diameter $<4 \mathrm{~mm}$; length $<20 \mathrm{~mm}$; fibromuscular dysplasia; significant renal artery stenosis) or in patients with an eGFR $<45 \mathrm{~mL} / \mathrm{min} / 1.73 \mathrm{~m}^{2}$. However, results from two small studies suggest that RDN might be efficient and safe in patients with moderate to severe chronic kidney disease $\left(\mathrm{n}=15 \text {; mean GFR } 31 \mathrm{~mL} / \mathrm{min} / 1.73 \mathrm{~m}^{2}\right)^{47}$ and in patients with end-stage renal disease. ${ }^{48}$

\section{Post-interventional follow-up}

Post-intervention follow-up visits should be recommended at $3,6,12,24,36,48$, and 60 months and should be carried out by a hypertension specialist. The follow-up visits should include the following: evaluation of current medication, physical examination, office blood pressure measurement, ambulatory blood pressure measurement, blood testing (serum electrolytes, glucose, and creatinine or cystatin C), urinary testing (urinary albumin excretion and salt excretion), and noninvasive imaging of renal arteries. ${ }^{36}$ 
Based on several case reports and experimental data of acute thrombus formation, antiplatelet therapy (eg, acetylsalicylic acid) is recommended for up to 4 weeks after $\mathrm{RDN}^{4}{ }^{49}$

To date, the reduction of antihypertensive drugs after RDN has not been systematically evaluated. Therefore, patients should be instructed to continue the medication, unless episodes of symptomatic hypotension are reported.

\section{Effects beyond blood pressure reduction}

RDN seems to have a number of beneficial effects beyond blood pressure reduction, which have been extensively reviewed elsewhere. ${ }^{50}$ Besides reducing peripheral blood pressure, RDN improved central hemodynamics and reduced arterial stiffness in 110 patients who underwent bilateral RDN. ${ }^{51}$ Transthoracic echocardiography revealed that RDN reduced left ventricular mass and improved diastolic function in patients with resistant hypertension. ${ }^{52}$ In that study, only 1 month after RDN, when blood pressure was slightly reduced, left ventricular mass was significantly reduced, and diastolic function was considerably improved, indicating that RDN might, at least in part, reduce myocardial hypertrophy independent of the changes in blood pressure.

Although RDN did not significantly reduce heart rate (HR) in the Symplicity HTN-1 trial, which included 45 patients, a recently published study of 136 subjects showed that RDN significantly reduced HR by $2.6 \pm 0.8$ and $2.1 \pm 1.1 \mathrm{bpm}$ after 3 and 6 months, respectively. ${ }^{53}$ The reduction of HR was related to HR at baseline with significantly higher reductions in the tertile of patients with HR $>71 \mathrm{bpm} .{ }^{53}$ This in line with the recently published EnligHTN I trial, in which RDN significantly reduced average HR. ${ }^{54}$ Importantly, increased HR is a predictor of mortality in cardiovascular disorders. ${ }^{55}$

In a pig model for OSA, RDN inhibited post-apneic blood pressure rises and attenuated pronounced shortening of atrial refractoriness and atrial fibrillation susceptibility as assessed on the day of RDN. ${ }^{56}$ In another animal model for paroxysmal atrial fibrillation by repetitive atrial stimulation, RDN effectively provided rate control during atrial fibrillation. ${ }^{57}$ Notably, both studies were conducted in an acute animal model for OSA and the effects of RDN were analyzed on the day of the procedure. In two patients with electrical storm due to hypertrophic cardiomyopathy and dilated cardiomyopathy, RDN significantly reduced ventricular tachyarrhythmias. ${ }^{58}$

In addition to cardiac effects, $\mathrm{RDN}$ reduced renal resistive indices and rates of albuminuria without comprising GFR. ${ }^{42}$
Finally, RDN improved glucose metabolism and insulin sensitivity in patients with resistant hypertension. ${ }^{59}$

Interestingly, these favorable effects of RDN were partly independent of blood pressure-lowering effect, pointing to an important role of reduced central sympathetic outflow. However, reduced central sympathetic outflow measured by norepinephrine spillover following RDN was only documented in few subjects. ${ }^{7,60}$ Recently, a reduction in sympathetic activity after RDN assessed by muscle sympathetic nerve activity in 25 patients with resistant hypertension has been published. ${ }^{47}$ Thus, further controlled clinical studies are needed to substantiate the potentially blood pressureindependent effects of RDN.

\section{Future perspectives}

Catheter-based RDN is a novel approach that effectively reduces blood pressure in patients with resistant hypertension. However, concerns have been raised that the favorable effects are in part due to a placebo effect based on changes in lifestyle and improved medical adherence. ${ }^{61}$ This issue will be addressed in the ongoing Symplicity HTN-3, a multicenter, prospective, single blind, randomized, placebo-controlled trial currently ongoing in the USA. ${ }^{62}$ More than 500 patients will be included and randomized in a single blinded 2:1 treatment design in 90 centers in the USA. ${ }^{63}$

Approximately $12 \%$ of patients did not significantly respond to RDN. ${ }^{23}$ However, besides a high SBP at baseline, no factors predicting response to $\mathrm{RDN}$ have been identified..$^{40}$ In addition, there are no indicators for procedural success. Therefore, the identification of markers predicting response to RDN, and showing the immediate efficacy of the procedure will be of major interest.

Uncontrolled hypertension is a well-established surrogate marker for cardiovascular outcomes. Nevertheless, clinical studies evaluating the impact of RDN on cardiovascular events will be conducted. Recently, St Jude Medical, Inc announced the start of the EnligHTNment clinical study ${ }^{64}$ EnligHTNment is a prospective, randomized, controlled study of approximately 4,000 patients with a $\mathrm{SBP} \geq 160 \mathrm{mmHg}$ enrolled around the world at up to 150 sites. Patients will be randomized to medical therapy plus RDN or medical therapy alone and will be followed for 5 years. Primary endpoints include major cardiovascular events such as heart attack, stroke, heart failure with hospitalization and cardiovascular death. Secondary endpoints include the reduction of in-office and ambulatory blood pressure and changes in renal function.

As RDN has been shown to reduce sympathetic nervous activity, it will be of major interest to systematically 
evaluate the effect of RDN on other diseases associated with increased sympathetic activity such as heart failure, OSA, atrial fibrillation, ventricular arrhythmias, chronic renal disease, and metabolic syndrome. These studies will help to further identify and characterize the sympatho-modulating effects of RDN.

\section{Acknowledgments}

$\mathrm{CU}, \mathrm{MB}$, and FM are supported by Deutsche Forschungsgemeinschaft (KFO 196). SE, DL, and FM are supported by Deutsche Hochdruckliga. DU, DL and FM are supported by Deutsche Gesellschaft für Kardiologie.

\section{Disclosure}

The institution has received scientific support from Medtronic/Ardian, St Jude Medical, Inc, Vessix, and ReCor Medical Technology. MB and FM are investigators of the Symplicity HTN-1 and HTN-2 trials. CU, MB, and FM have received speaker honorarium and consulting fees from Medtronic/Ardian and St Jude Medical, Inc. DU, SE, and DL declare no conflicts of interest in this work.

\section{References}

1. Fagard RH. Resistant hypertension. Heart. 2012;98(3):254-261.

2. Calhoun DA, Jones D, Textor S, et al; American Heart Association Professional Education Committee. Resistant hypertension: diagnosis, evaluation, and treatment: a scientific statement from the American Heart Association Professional Education Committee of the Council for High Blood Pressure Research. Circulation. 2008;117(25): e510-e 526.

3. Daugherty SL, Powers JD, Magid DJ, et al. Incidence and prognosis of resistant hypertension in hypertensive patients. Circulation. 2012;125(13):1635-1642.

4. Grassi G. Assessment of sympathetic cardiovascular drive in human hypertension: achievements and perspectives. Hypertension. 2009;54(4): 690-697.

5. DiBona GF, Kopp UC. Neural control of renal function. Physiol Rev. 1997;77(1):75-197.

6. Tsioufis C, Kordalis A, Flessas D, et al. Pathophysiology of resistant hypertension: the role of sympathetic nervous system. Int J Hypertens. 2011:642416.

7. Krum H, Schlaich M, Whitbourn R, et al. Catheter-based renal sympathetic denervation for resistant hypertension: a multicentre safety and proofof-principle cohort study. Lancet. 2009;373(9671):1275-1281.

8. Symplicity HTN-2 Investigators, Esler MD, Krum H, et al. Renal sympathetic denervation in patients with treatment-resistant hypertension (The Symplicity HTN-2 Trial): a randomised controlled trial. Lancet. 2010;376(9756):1903-1909.

9. Mancia G. Optimal control of blood pressure in patients with diabetes reduces the incidence of macro and microvascular events. J Hypertens Suppl. 2007;25(1):S7-S12.

10. Persell SD. Prevalence of resistant hypertension in the United States, 2003-2008. Hypertension. 2011;6(57):1076-1080.

11. Lloyd-Jones DM, Evans JC, Larson MG, O’Donnell CJ, Roccella EJ, Levy D. Differential control of systolic and diastolic blood pressure: factors associated with lack of blood pressure control in the community. Hypertension. 2000;36(4):594-599.
12. Löwel H, Meisinger C, Heier M, Hymer H, Alte D, Völzke H. Epidemiology of hypertension in Germany. Selected results of population-representative cross-sectional studies. Dtsch Med Wochenschr. 2006;131(46):2586-2591. German.

13. Dahlöf B, Sever PS, Poulter NR, et al; ASCOT Investigators. Prevention of cardiovascular events with an antihypertensive regimen of amlodipine adding perindopril as required versus atenolol adding bendroflumethiazide as required, in the Anglo-Scandinavian Cardiac Outcomes Trial-Blood Pressure Lowering Arm (ASCOTBPLA): a multicentre randomised controlled trial. Lancet. 2005;366 (9489):895-906.

14. Gupta AK, Nasothimiou EG, Chang CL, Sever PS, Dahlöf B, Poulter NR; ASCOT investigators. Baseline predictors of resistant hypertension in the Anglo-Scandinavian Cardiac Outcome Trial (ASCOT): a risk score to identify those at high-risk. J Hypertens. 2011;29(10):2004-2013.

15. Clark D III, Ahmed MI, Calhoun DA. Resistant hypertension and aldosterone: an update. Can J Cardiol. 2012;28(3):318-325.

16. Thoenes M, Tebbe U, Rosin L, et al. Blood pressure management in a cohort of hypertensive patients in Germany treated by cardiologists. Clin Res Cardiol. 2011;100(6):483-491.

17. Amar J, Chamontin B, Genes N, Cantet C, Salvador M, Cambou JP. Why is hypertension so frequently uncontrolled in secondary prevention? J Hypertens. 2003;21(6):1199-1205.

18. Chan CC, Reid CM, Aw TJ, Liew D, Haas SJ, Krum H. Do COX-2 inhibitors raise blood pressure more than nonselective NSAIDs and placebo? An updated meta-analysis. J Hypertens. 2009;27(12):2332-2341.

19. Makris A, Seferou M, Papadopoulos DP. Resistant hypertension workup and approach to treatment. Int J Hypertens. 2010;2011:598694.

20. Václavík J, Sedlák R, Plachy M, et al. Addition of spironolactone in patients with resistant arterial hypertension (ASPIRANT): a randomized, double-blind, placebo-controlled trial. Hypertension. 2011;57(6): 1069-1075.

21. Gonçalves SC, Martinez D, Gus M, et al. Obstructive sleep apnea and resistant hypertension: a case-control study. Chest. 2007;132(6): 1858-1862.

22. Pratt-Ubunama MN, Nishizaka MK, Boedefeld RL, Cofield SS, Harding SM, Calhoun DA. Plasma aldosterone is related to severity of obstructive sleep apnea in subjects with resistant hypertension. Chest. 2007;131(2):453-459.

23. Mahfoud F, Himmel F, Ukena C, Schunkert H, Böhm M, Weil J. Treatment strategies for resistant arterial hypertension. Dtsch Arztebl Int. 2011;108(43):725-731.

24. Pickering TG, Hall JE, Appel LJ, et al. Recommendations for blood pressure measurement in humans and experimental animals: part 1: blood pressure measurement in humans: a statement for professionals from the Subcommittee of Professional and Public Education of the American Heart Association Council on High Blood Pressure Research. Circulation. 2005;111(5):697-716.

25. Brown MA, Buddle ML, Martin A. Is resistant hypertension really resistant? Am J Hypertens. 2001;14(12):1263-1269.

26. de la Sierra A, Segura J, Banegas JR, et al. Clinical features of 8295 patients with resistant hypertension classified on the basis of ambulatory blood pressure monitoring. Hypertension. 2011;57(5): 898-902.

27. Vrijens B, Vincze G, Kristanto P, Urquhart J, Burnier M. Adherence to prescribed antihypertensive drug treatments: longitudinal study of electronically compiled dosing histories. BMJ. 2008;336(7653): 1114-1117.

28. Garg JP, Elliott WJ, Folker A, Izhar M, Black HR; RUSH University Hypertension Service. Resistant hypertension revisited: a comparison of two university-based cohorts. Am J Hypertens. 2005;18(5 Pt 1): 619-626.

29. Effects of treatment on morbidity in hypertension. Results in patients with diastolic blood pressures averaging 115 through $129 \mathrm{~mm} \mathrm{Hg}$. JAMA. 1967;202(11):1028-1034. 
30. Esler M. The sympathetic system and hypertension. Am J Hypertens. 2000;13(6 Pt 2):99S-105S.

31. Grassi G, Cattaneo BM, Seravalle G, Lanfranchi A, Mancia G. Baroreflex control of sympathetic nerve activity in essential and secondary hypertension. Hypertension. 1998;31(1):68-72.

32. Greenwood JP, Stoker JB, Mary DA. Single-unit sympathetic discharge: quantitative assessment in human hypertensive disease. Circulation. 1999;100(12):1305-1310.

33. Schlaich MP, Esler MD. Sympathetic nerve activity in essential hypertension. New pathophysiologic aspects. Dtsch Med Wochenschr. 2003;128(13):677-681. German.

34. Campese VM, Kogosov E. Renal afferent denervation prevents hypertension in rats with chronic renal failure. Hypertension. 1995; 25(4 Pt 2):878-882.

35. Mahfoud F, Lüscher TF, Andersson B, et al. Expert consensus document from the European Society of Cardiology on catheter-based renal denervation. Eur Heart J. Epub June 25, 2013.

36. Mahfoud F, Vonend O, Bruck H, et al; Arbeitsgemeinschaft Herz und Niere der Deutschen Gesellschaftfür Kardiologie - Herz- und Kreislaufforschunge $V$ und der Deutschen Gesellschaft für Nephrologiee V sowie der Deutschen Hochdruckliga e V DHL ${ }^{\circledR}$ - DeutscheGesellschaft für Hypertonie und Prävention. [Expert consensus statement on interventional renal sympathetic denervation for hypertension treatment.] Dtsch Med Wochenschr. 2011;136(47):2418. German.

37. Schmieder RE, Redon J, Grassi G, et al. ESH position paper: renal denervation - an interventional therapy of resistant hypertension. J Hypertens. 2012;30(5):837-841.

38. Krum H, Barman N, Schlaich M, Sobotka P, Esler M, Mahfoud F. Long-term follow-up of catheter-based renal sympathetic denervation for resistant hypertension confirms durable blood pressure reduction. J Am Coll Cardiol. 2012;59(13 s1):E1704-E1704.

39. Esler MD, Krum H, Schlaich M, Schmieder RE, Böhm M, Sobotka PA; Symplicity HTN-2 Investigators. Renal sympathetic denervation for treatment of drug-resistant hypertension: one-year results from the Symplicity HTN-2 randomized, controlled trial. Circulation. 2012;126(25):2976-2982.

40. Mahfoud F, Ukena C, Schmieder RE, et al. Ambulatory blood pressure changes after renal sympathetic denervation in patients with resistant hypertension. Circulation. Epub June 18, 2013.

41. Symplicity HTN-1 Investigators. Catheter-based renal sympathetic denervation for resistant hypertension: durability of blood pressure reduction out to 24 months. Hypertension. 2011;57(5):911-917.

42. Mahfoud F, Cremers B, Janker J, et al. Renal hemodynamics and renal function after catheter-based renal sympathetic denervation in patients with resistant hypertension. Hypertension. 2012;60(2):419-424.

43. Dörr O, Liebetrau C, Möllmann H, et al. Renal sympathetic denervation does not aggravate functional or structural renal damage. $\mathrm{J} \mathrm{Am} \mathrm{Coll}$ Cardiol. 2013;61(4):479-480.

44. Kaltenbach B, Id D, Franke JC, et al. Renal artery stenosis after renal sympathetic denervation. J Am Coll Cardiol. 2012;60(25):2694-2695.

45. Vonend O, Antoch G, Rump LC, Blondin D. Secondary rise in blood pressure after renal denervation. Lancet. 2012;380(9843):778.

46. Ukena C, Mahfoud F, Kindermann I, et al. Cardiorespiratory response to exercise after renal sympathetic denervation in patients with resistant hypertension. J Am Coll Cardiol. 2011;58(11):1176-1182.

47. Hering D, Mahfoud F, Walton AS, et al. Renal denervation in moderate to severe CKD. J Am Soc Nephrol. 2012;23(7):1250-1257.

48. Schlaich MP, Bart B, Hering D, et al. Feasibility of catheter-based renal nerve ablation and effects on sympathetic nerve activity and blood pressure in patients with end-stage renal disease. Int J Cardiol. Epub February 28, 2013.
49. Steigerwald K, Titova A, Malle C, et al. Morphological assessment of renal arteries after radiofrequency catheter-based sympathetic denervation in a porcine model. J Hypertens. 2012;30(11):2230-2239.

50. Böhm M, Linz D, Urban D, Mahfoud F, Ukena C. Renal sympathetic denervation: applications in hypertension and beyond. Nat Rev Cardiol. Epub June 18, 2013.

51. Brandt MC, Reda S, Mahfoud F, Lenski M, Böhm M, Hoppe UC. Effects of renal sympathetic denervation on arterial stiffness and central hemodynamics in patients with resistant hypertension. $\mathrm{J} \mathrm{Am} \mathrm{Coll}$ Cardiol. 2012;60(19):1956-1965.

52. Brandt MC, Mahfoud F, Reda S, et al. Renal sympathetic denervation reduces left ventricular hypertrophy and improves cardiac function in patients with resistant hypertension. $\mathrm{J} \mathrm{Am} \mathrm{Coll} \mathrm{Cardiol.}$ 2012;59(10):901-909.

53. Ukena C, Mahfoud F, Spies A, et al. Effects of renal sympathetic denervation on heart rate and atrioventricular conduction in patients with resistant hypertension. Int J Cardiol. 2012;Epub ahead of print.

54. Worthley SG, Tsioufis CP, Worthley MI, et al. Safety and efficacy of a multi-electrode renal sympathetic denervation system in resistant hypertension: the EnligHTN I trial. Eur Heart J. Epub June 19, 2013.

55. Reil JC, Custodis F, Swedberg K, et al. Heart rate reduction in cardiovascular disease and therapy. Clin Res Cardiol. 2011;100(1):11-19.

56. Linz D, Mahfoud F, Schotten U, et al. Renal sympathetic denervation suppresses postapneic blood pressure rises and atrial fibrillation in a model for sleep apnea. Hypertension. 2012;60(1):172-178.

57. Linz D, Mahfoud F, Schotten U, et al. Renal sympathetic denervation provides ventricular rate control but does not prevent atrial electrical remodeling during atrial fibrillation. Hypertension. 2013;61(1): 225-231.

58. Ukena C, Bauer A, Mahfoud F, et al. Renal sympathetic denervation for treatment of electrical storm: first-in-man experience. Clin Res Cardiol. 2012;101(1):63-67.

59. Mahfoud F, Schlaich M, Kindermann I, et al. Effect of renal sympathetic denervation on glucose metabolism in patients with resistant hypertension: a pilot study. Circulation. 2011;123(18):1940-1946.

60. Schlaich MP, Straznicky N, Grima M, et al. Renal denervation: a potential new treatment modality for polycystic ovary syndrome? J Hypertens. 2011;29(5):991-996.

61. Persu A, Renkin J, Thijs L, Staessen JA. Renal denervation: ultima ratio or standard in treatment-resistant hypertension. Hypertension. 2012;60(3):596-606.

62. Medtronic Vascular. Global SYMPLICITY Registry. In: ClinicalTrials. gov [website on the Internet]. Bethseda, MD: US National Library of Medicine; 2012 [updated April 18, 2013]. Available from: http://clinicaltrials.gov/ct2/show/NCT01534299. NLM identifier: NCT01534299. Accessed July 1, 2013.

63. Kandzari DE, Bhatt DL, Sobotka PA, et al. Catheter-based renal denervation for resistant hypertension: rationale and design of the SYMPLICITY HTN-3 Trial. Clin Cardiol. 2012;35(9):528-535.

64. St. Jude Medical Initiates Landmark Study of Renal Denervation for Reduction of Heart Attack, Stroke and Death [press release]. St Paul, MN. Available from: http://investors.sjm.com/phoenix. zhtml?c=73836\&p=irol-newsArticle \&ID=1785544. Accessed July 25, 2013. 
Integrated Blood Pressure Control

Dovepress

\section{Publish your work in this journal}

Integrated Blood Pressure Control is an international, peer-reviewed open-access journal focusing on the integrated approach to managing hypertension and risk reduction. Treating the patient and comorbidities together with diet and lifestyle modification and optimizing healthcare resources through a multidisciplinary team approach constitute key

features of the journal. This journal is indexed on American Chemical Society's Chemical Abstracts Service (CAS). The manuscript management system is completely online and includes a very quick and fair peerreview system, which is all easy to use. Visit http://www.dovepress.com/ testimonials.php to read real quotes from published authors.

Submit your manuscript here: http://www.dovepress.com/integrated-blood-pressure-control-journal 